\title{
The Significance of Organizational Culture and Leadership Behaviour on Organizational Success
}

\author{
Olatunji David Adekoya ${ }^{1}$, Ibrahim Jimoh $^{2}$, Monisola Olajide ${ }^{3}$, Femi Olawoyin ${ }^{4}$ \\ ${ }^{I}$ Faculty of Business and Management, University of Wales Trinity Saint David, United Kingdom \\ ${ }^{2}$ Department of Business and Entrepreneurship, Kwara State University, Nigeria \\ ${ }^{3}$ Department of Accounting, Kwara State University, Nigeria \\ ${ }^{4}$ Department of Business and Entrepreneurship, Kwara State University, Nigeria
}

\begin{abstract}
This study examines the interconnection between organizational culture, leadership behaviour and organizational success and create an empirical link based on data drawn from one of Nigeria's Cement Manufacturing Companies. This research was conducted using the quantitative method across the staff in the selected company. Semi-structured questionnaires were distributed to a population sample of 63 participants. From the results, there exists a significant relationship between these three elements while the organizational cultural type and style of leadership enforces the existing relationship. It was discovered that organizational culture which refers to the beliefs and values that have existed in an organization for a long time, and to the beliefs of the staff and the foreseen value of their work that will influence their attitudes and behaviour. We established that administrators or top management officers tend to modify their leadership behaviour to achieve the organization's goals which in turn often influence job satisfaction on the part of the employee. It was also ascertained that there was a positive link between organization culture, leadership behaviour and organizational success. Findings also revealed that the culture of the organization has a two-way effect on the success of the organization, likewise the leadership traits and behaviour.
\end{abstract}

Keywords: Leadership behaviour, organizational success, traits, organization culture, job satisfaction

\subsection{INTRODUCTION}

Many ongoing researches have been directed towards understanding the importance of organization culture on business performance and also evaluating the role of leadership behaviour in attaining organization success. On the one hand, the culture of an organization includes the values, beliefs, assumptions and approaches undertaken to influence its operational activities and business performance. On the other hand, the type of leadership behaviour elicited by leaders or superiors in their dealings with the lower cadre staff is a critical factor for measuring organization success (Al-Hussami et al., 2018). Nuckcheddy (2018) opined that the leadership role is dependent on the personality of the leaders and how they are able to act upon motivation to promote a positive organizational behaviour.

It is not farfetched to consolidate the efforts of leaders or top management staffs and how they are able to influence the middle and lower management staffs towards achieving the goals and objectives of the organization; as such there are still a number of criteria that need to be considered to ensure that the culture and leadership behaviour in organizations is able to positively influence business performance.

The role of HR departments in ensuring that employees are well familiar with the culture of the organization cannot be underestimated. Besides, HR practitioners have a singular role to portray the right attitude to work, and ensure that there are interactive measures put in place to create a convergence among the entire workforce which is expected to translate into positive outcomes for the organization (Al-Hussami et al., 2018).

The research is therefore, aimed at investigating the significance of organizational culture and leadership behaviour on organization success. The study will, therefore, serve as a blueprint for understanding the roles of culture and leadership behaviour on the performance of an organization. 


\subsection{Research Question}

The main question asked in this study is, 'Does organizational culture and leadership behaviour have any significance on the success of an organization?' However, to create a better understanding on the context of this study, the following are the specific questions:

1. Is there any significance of organizational culture on the overall success of an organization?

2. What is the relationship between leadership behaviour and organizational success?

3. Is there a link between the culture and leadership behaviour inherent in an organization on its general performance?

\subsection{Research Aim and Objectives}

The aim of the study is to determine and analyze the relationship between organizational culture and the leadership behaviour of an organization on the success of the organization. However, the specific objectives are to:

1. Evaluate the significance of organizational culture on the overall success of an organization.

2. Examine the relationship between leadership behaviour and organizational success.

3. Analyse the link between organizational culture, leadership behaviour and organizational performance.

\subsection{LITERATURE REVIEW}

\subsection{Organizational Culture}

The organizational culture is likened to a double-edged sword and depicts the form of group identity and shared belief, feelings and thought. Cultures differentiates organizations from one another as it expresses a sense of recognition for its staff, ensures dedication towards the organization's objective, ensure sustainability of social structure, reduces complexity, and serve as a control tool that mold the attitude of the staff (Ilham, 2018; Zeyada 2018, Christensen, 2006). However, culture becomes a responsibility when encroached into the belief and values of the employees; it could become a hindrance to changes, diversification and other factors that are required by an organization to adapt in today's globalized and changing business environment (Daft, 2005).

Robbins (2005) implied that organizational culture study takes a myriad of elements. It was further expatiated by focusing on the seven primary features that capture the importance of organizational culture which include; introduction of something new and risk-taking, paying keen attention to detail, result orientation, team orientation, people orientation, aggressiveness and stability. These features can exist on a continuum from low to high and also the perception of employees regarding the organization based on the seven factors will affect their performance either positively or otherwise.

\subsection{Leadership Behavior}

Leadership is both a research area and a practical skill combining the ability of an individual or a company to lead other individuals or the entire organization. Each leadership behaviour has both advantages and disadvantages with regard to coordinating employees of the organization (Aydin, 2018). An essential opinion is the extent to which the leadership behaviour, organizational culture and the objective of the organization agree with one another. However, some organizations adopt different leadership behaviour depending on the task to be accomplished (Chin, 2015).

Daft (2005) defined leadership as a driving relationship among the leaders and the followers who are ready to put their efforts together to achieve an objective and a shared purpose. As time goes by, researchers have been developing and applying different scopes of leadership behaviour to find out what influence leadership success and failure. These include but not limited to autocratic against democratic, task-oriented against people-oriented and the contingency approaches. 


\section{Transformational and Transactional Leadership}

Theoretically, transformational and transactional leadership creates respect, honesty and work dedication towards the same direction. On the one hand, transactional leadership exhibits the task-oriented relationship by assigning effort using reward and punishment strategy to drive followers desire to complete a task (Walumbwa, F. \&Orwa, B. 2008). As the reward and punishment strategy can motivate the followers, so also can it discourage followers if an agreement cannot be negotiated (Faraz et al., 2018; Burke, 2006). On the other hand, transactional leadership is regarded as being a necessity to be employed occasionally and as such, the relationship between a leader and follower are based on work performance and reward. This encourages supports between leader and follower when an agreement needs to be made to discuss an important issue (Bass \& Avolio, 2004; Kalsoom, 2018).

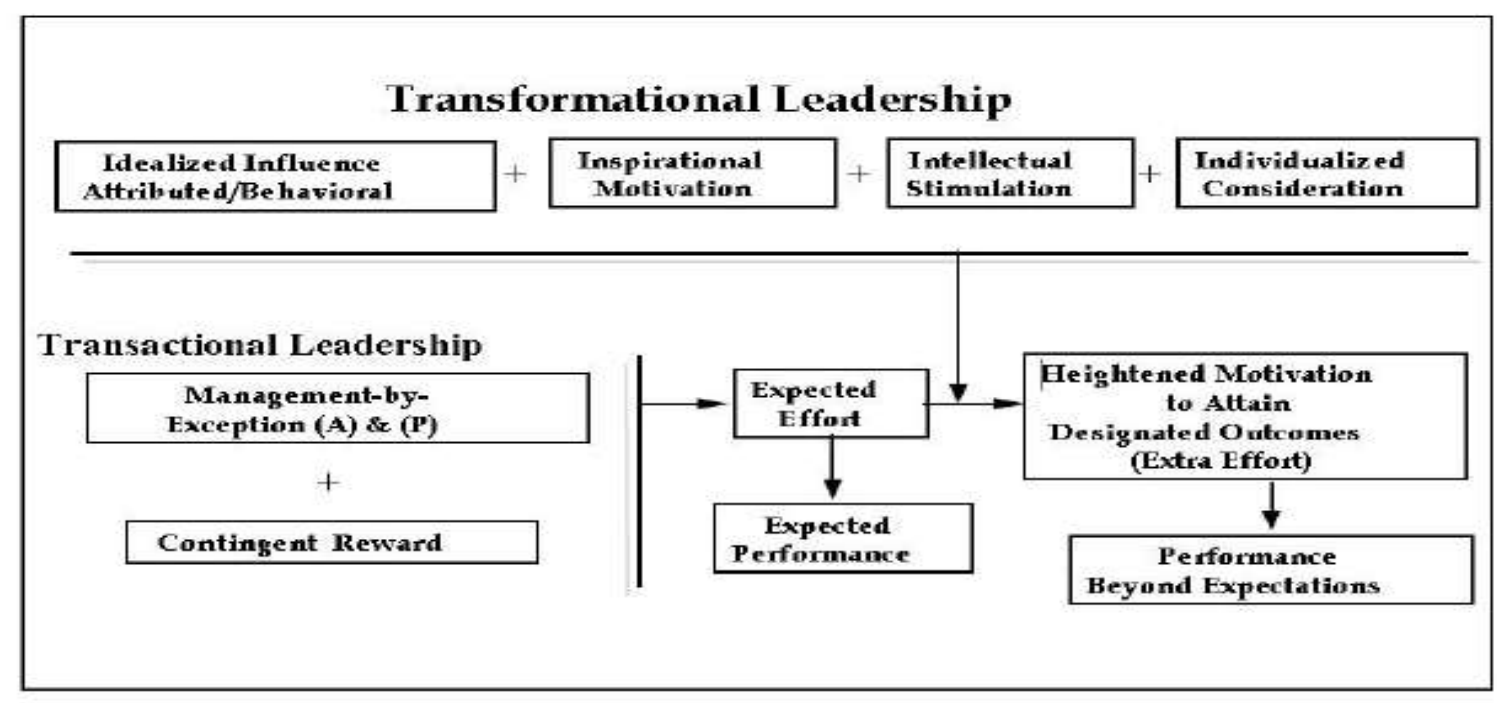

Fig 1: Transformational and Transactional Leadership (Bernard Bass \& Bruce Avolio, 2004)

\subsection{The link between Organizational Culture, Leadership Behaviour and Organization Performance}

According to Cascio (2006 cited in Collins et al., 2018), performance refers to the degree of success and the accomplishment of the motive that builds up an employee job (Cascio, 2006). Daft (2000), explained that organization success is the organization's ability to achieve its objective effectively and efficiently using raw materials and personnel. Also, Richardo (2001) insinuated that organization success leads to an increase in shareholders' wealth and this is achieved as a result of effective staff performance management system.

According to Yafang (2011), Organizational culture expresses shared norms, values and assumptions which serve as important elements that bind an organization together. How the employee of an organization behave is spelt out by the organizational culture, and a strong and effective culture enhance common codes of conducts that guides the employee which translates into organizational success.

Organization success has been attached to employees who see their managers to be supporting. A caring leader shares values in a balance of power and gives the subordinates the opportunity to share their opinion which reduces the chances of internal misunderstanding. A leader that display a caring behaviour will be successful in achieving his aims and objectives thereby preserving power and status within the organization. A supporting leader is respected and usually has the executive power to accomplish the necessary task as well as creating a positive working environment. The behaviour of the manager directly has a measurable effect on the morale of the employee and organization as a whole (Yafang, 2011; Zeyada, 2018).

Organizational culture is a major element that determines employee dedication and motivation which leads to organization success. Previous works of literature on the relationship between leadership and culture unveil different forms of behaviour which is based on the culture environment. The differences come from diverse workforce approaches, and also leadership behaviour fluctuates culture to culture (Dorfman \&Hanges, 2011; Ilham, 2018). Various researches demonstrated the connection between organizational culture and leadership behaviour. Schimmoeller (2010) carried out research on leadership behaviour and its effect on culture 
and discovered that transactional leaders perform in within an existing culture, while transformation leaders operate to put together both the culture and the vision of the organization. Jogulu (2010) established that the leadership behaviour within an organization changes as the organizational culture changes. The culture and leadership behaviour affect the organization success either positively or negatively depending on how the employees perceive the system within the organization.

\subsection{Theoretical Review}

Organizational culture and leadership behaviour are one of the essential determinants of organizational success. The following discussion explains the culture and leadership theories in the literature.

\subsubsection{Schein's Theory of Organizational Culture}

This theory consists of three aspects which are the basic underlying assumptions, espoused values, and artifacts. Artifacts are the elementary level which is tangible and easily felt; it includes environment, language, technology, values, clothing and occasions (James \& Jones, 2005). Espoused values include strategies, objectives, shared belief established by the leader or manager.

According to James \& Jones (2005), the basic underlying assumptions are the base level of organizational culture which are unintentionally not taken assumptions seriously, but which greatly affect organization success. This theory has been chosen to support this study because it proposes that the basic underlying assumptions, espoused values and artifacts should reflect in organizational culture in order to achieve organizational success.

\subsubsection{Behavioural Theory}

Behavioural theory is a leadership theory that can be associated to organization success because it is geared towards understanding leaders' activities and how the activities relate to leadership effectiveness which enhances organizational success. This theory explains that in order for leaders to guide followers towards achieving organization success, the leader must cope with two different but interrelated aspects of their situation. The objective must be achieved with the contribution of the employee (Gibson, 2003). Behavioural theory studied leadership behaviour by analyzing the duties of the leader regarding achieving the organization objective as well as maintaining the values of those performing the task. Therefore, behaviour is a major factor of leadership and people could be trained to be a leader (Robbins 2001).

\subsection{Research Design}

\subsection{RESEARCH METHODOLOGY}

This research work employs the critical realism philosophy as it focuses on the understanding of what is seen and experienced (Bryman\& Bell, 2015) in terms of the significance of culture and leadership behaviour on the success of the organization. The deductive approach to research is used as it follows the path from ideas and examines the ideas against the findings of the undertaken study (Bryman \& Bell, 2015). It adopted the quantitative research method to derive adequate answers to the designed research questions.

\subsection{Data Sources and Collection}

This study adopted quantitative approach to research using a semi-structured questionnaire as the research instrument for the collection of primary data. Data were also obtained from secondary sources through a variety of existing literature to enable data triangulation and support the research findings. The researchers carried out the study on one of the top cement manufacturing companies in Nigeria. The researchers in adherence to the data protection policy has kept the information of the participants confidential, likewise the name of the company where the data was gathered.

\subsection{Sample Size and Sampling Technique}

Choosing the number of observations or replicates to include in a statistical sample, the Taro Yamane method was used. This study adopts random sampling technique, it is a sample of a given size in which all such subsets of the frame are given an equal probability to be chosen, each element has an equal probability of selection. The Taro Yamane method for sample size calculation is used to determine the sample size from a given population. Below is the mathematical illustration for the Taro Yamane method: 
$\mathrm{n}=$

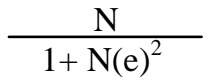

Where;

$\mathrm{n}=$ the sample size

$\mathrm{N}=$ the population size

$\mathrm{e}=$ the acceptable sample error

Therefore, using the population size of 75 , the sample size would be:

$\mathrm{N}=75, \mathrm{e}=0.05$

Using the formulae;

$\mathrm{n}=63.16$

$\mathrm{n}=63$

\subsection{Method of Data Analysis}

This research work adopts the deductive and quantitative method of analysis which analyses the range of processes and procedures whereby we move from the qualitative data that have been gathered, coded, explained, understood or interpreted based on the situation factors and people that are being investigated. The data analysis tool used for this study was the Statistical Package for Social Sciences (SPSS) and Microsoft Excel. This study employs the use of regression analysis and correlation model to establish the relationship between the measured variables, that is, organization culture, leadership behaviour and organization success.

\subsection{DATA ANALYSIS}

This section of the study demonstrates how the data that was gathered from the questionnaires have been analyzed and interpreted. As such, the researchers employed the use of tables, bar charts and pie charts to describe the variables and give proper interpretations.

\section{The Organization has a Healthy Work Culture}

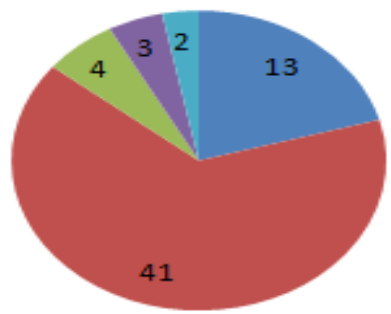

Fig 2: The level of healthy work culture and its effect on the success of the organization.

From the above charts, it is indicated that a significant population of the respondents view thatthe organization has a healthy culture and has also contributed to the organization's success.
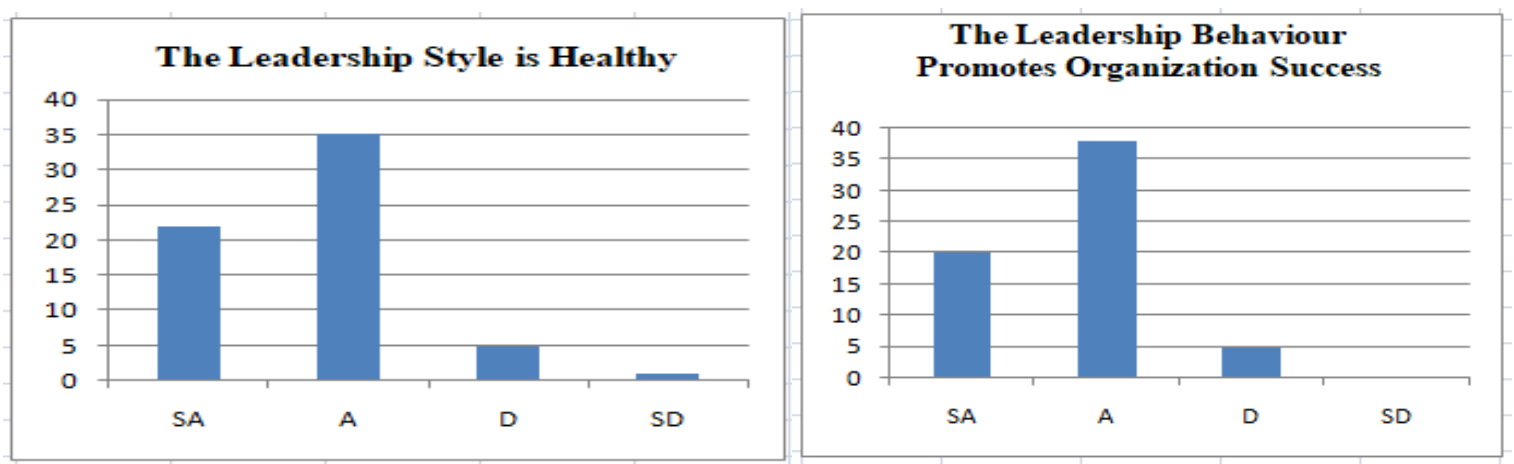

Fig 3: The level of healthy leadership behaviour and its effect on the success of the organization. 
The above charts indicate that a significant population of the respondents view that the organization has a healthy leadership style and has also contributed to the organization's success.

$\mathrm{H}_{1}$ : There is no significant relationship between organizational culture and the overall success of an organization.

Table 1. Correlation Coefficient for Organization Culture and Organization Success

\begin{tabular}{|c|c|c|c|}
\hline & & $\begin{array}{c}\text { Organization } \\
\text { Culture }\end{array}$ & $\begin{array}{c}\text { Organization } \\
\text { Success }\end{array}$ \\
\hline \multicolumn{2}{|l|}{ Correlation } & 1.000 & $.702 * *$ \\
\hline Organization & Coefficient & & \\
\hline Culture & Sig. (2-tailed) & . & .000 \\
\hline Spearman's rho & $\mathrm{N}$ & 63 & 63 \\
\hline \multicolumn{2}{|l|}{ Correlation } & $.702 * *$ & 1.000 \\
\hline Organization & Coefficient & & \\
\hline Success & Sig. (2-tailed) & .000 & \\
\hline & $\mathrm{N}$ & 63 & 63 \\
\hline
\end{tabular}

**. Correlation is significant at 0.05 level (2-tailed).

From the correlation analysis table above, the result shows that there exist a significant relationship between organization culture and organization success since there is a value of 0.702 . In addition, the null hypothesis does not hold and is therefore rejected because the p-value $0.000<0.05$ where 0.05 is the selected level of significance to test for any form of relationship between the variables. Therefore, the result reveals that the relationship between the organization's culture and its success is statistically significant.

Table 2. Coefficients ${ }^{\mathrm{a}}$

\begin{tabular}{|c|r|r|r|r|r|}
\hline \multirow{2}{*}{ Model } & \multicolumn{2}{|c|}{$\begin{array}{c}\text { Unstandardized } \\
\text { Coefficients }\end{array}$} & \multicolumn{2}{c|}{$\begin{array}{c}\text { Standardized } \\
\text { Coefficients }\end{array}$} & \multirow{2}{*}{ Sig. } \\
\cline { 2 - 5 } & \multicolumn{1}{|c|}{ B } & Std. Error & Beta & & \\
\hline (Constant) & 1.334 & .294 & & 4.751 & .000 \\
1 Organization Culture & .721 & .082 & .679 & 6.899 & .000 \\
\hline
\end{tabular}

a. Dependent Variable: Organization Success

From the regression analysis table as presented above, the result showcases that there are evidences of relationship between organization success (the dependent variable) and organization culture (the independent variable). The correlation coefficients indicate that both variables are statistically significant. Also, given that the beta value is 0.679 shows that the organization's culture has a $67.9 \%$ effect on the success of the organization. In addition, the null hypothesis does not hold and is therefore also rejected since the p-value $0.000<0.05$ where 0.05 is the selected level of significance to test for any form of relationship between the variables. Therefore, the result reveals a strong relationship between the organization's culture and its success.

$\mathrm{H}_{2}$ : There is no significant relationship between leadership behaviour and organizational success.

Table 3. Correlation Coefficient for Leadership Behaviour and Organization Success

\begin{tabular}{|cc|r|r|}
\hline & & $\begin{array}{c}\text { Leadership } \\
\text { Behaviour }\end{array}$ & \multicolumn{1}{c|}{$\begin{array}{c}\text { Organization } \\
\text { Success }\end{array}$} \\
\hline Correlation & Coefficient & 1.000 & $.857^{* *}$ \\
Leadership & Sig. (2-tailed) & .000 \\
Behaviour & $\mathrm{N}$ & 63 & 63 \\
$\begin{array}{c}\text { Spearman's rho } \\
\text { Correlation }\end{array}$ & Coefficient & $.857 * *$ & 1.000 \\
Organization & Sig. (2-tailed) & .000 &. \\
Success & $\mathrm{N}$ & 63 & 63 \\
\hline
\end{tabular}


**. Correlation is significant at 0.05 level (2-tailed).

From the correlation analysis table above, the result shows that there exist a significant relationship between leadership behaviour and organization success since there is a value of 0.857 . In addition, the null hypothesis does not hold and is therefore rejected because the p-value $0.000<0.05$ where 0.05 is the selected level of significance to test for any form of relationship between the variables. Therefore, the result reveals that the relationship between the leadership behaviour in the organization and its success is statistically significant.

Table 4. Coefficients ${ }^{\mathrm{a}}$

\begin{tabular}{|c|c|c|c|c|c|c|}
\hline \multirow{2}{*}{\multicolumn{2}{|c|}{ Model }} & \multicolumn{2}{|c|}{$\begin{array}{c}\text { Unstandardized } \\
\text { Coefficients }\end{array}$} & \multirow{2}{*}{$\begin{array}{l}\begin{array}{l}\text { Standardized } \\
\text { Coefficients }\end{array} \\
\text { Beta }\end{array}$} & \multirow[t]{2}{*}{$\mathrm{T}$} & \multirow[t]{2}{*}{ Sig. } \\
\hline & & $\mathrm{B}$ & Std. Error & & & \\
\hline 1 & $\begin{array}{l}\text { (Constant) } \\
\text { Leadership } \\
\text { Behaviour }\end{array}$ & $\begin{array}{r}1.452 \\
.883\end{array}$ & $\begin{array}{l}.304 \\
.093\end{array}$ & .773 & $\begin{array}{l}4.833 \\
6.937\end{array}$ & $\begin{array}{l}.000 \\
.000\end{array}$ \\
\hline
\end{tabular}

a. Dependent Variable: Organization Success

From the regression analysis table as presented above, the result showcases that there are evidences of relationship between organization success (the dependent variable) and leadership behaviour (the independent variable). The correlation coefficients indicate that both variables are statistically significant. Also, given that the beta value is 0.773 shows that the organization's leadership behaviour has a $77.3 \%$ effect on the success of the organization. In addition, the null hypothesis does not hold and is therefore also rejected since the p-value $0.000<0.05$ where 0.05 is the selected level of significance to test for any form of relationship between the variables. Therefore, the result reveals a strong relationship between the organization's leadership behaviour and its success.

\section{$\mathrm{H}_{3}$ : There is no link between the culture and leadership behaviour inherent in an organization on its general performance.}

Table 5. Correlation Coefficient for Culture, Leadership Behaviour and Organization Success

\begin{tabular}{|c|c|c|c|}
\hline & & $\begin{array}{l}\text { Culture and } \\
\text { Leadership } \\
\text { Behaviour }\end{array}$ & $\begin{array}{l}\text { Organization } \\
\text { Success }\end{array}$ \\
\hline $\begin{array}{l}\text { Culture } \\
\text { and Leadership } \\
\text { Behaviour } \\
\text { Spearman's rho } \\
\text { Correlation } \\
\text { Organization } \\
\text { Success }\end{array}$ & $\begin{array}{l}\text { Correlation } \\
\text { Coefficient } \\
\text { Sig. (2-tailed) } \\
\text { N } \\
\text { Coefficient } \\
\text { Sig. (2-tailed) } \\
\text { N }\end{array}$ & $\begin{array}{r}1.000 \\
63 \\
.824 * * \\
.000 \\
63\end{array}$ & $\begin{array}{r}.824 * * \\
.000 \\
63 \\
1.000 \\
\\
63\end{array}$ \\
\hline
\end{tabular}

**. Correlation is significant at 0.05 level (2-tailed).

Table 6. Coefficients ${ }^{\mathrm{a}}$

\begin{tabular}{|c|c|c|c|c|c|}
\hline \multirow[t]{2}{*}{ Model } & \multicolumn{2}{|c|}{$\begin{array}{c}\text { Unstandardized } \\
\text { Coefficients }\end{array}$} & $\begin{array}{l}\text { Standardized } \\
\text { Coefficients }\end{array}$ & $\mathrm{T}$ & Sig. \\
\hline & B & Std. Error & Beta & & \\
\hline $\begin{array}{ll} & \text { (Constant) } \\
1 \quad & \text { Culture and } \\
& \text { Leadership } \\
& \text { Behaviour }\end{array}$ & $\begin{array}{r}1.359 \\
.822\end{array}$ & $\begin{array}{l}.296 \\
.088\end{array}$ & .740 & $\begin{array}{l}4.789 \\
6.871\end{array}$ & $\begin{array}{l}.000 \\
.000\end{array}$ \\
\hline
\end{tabular}

a. Dependent Variable: Organization Success

From the correlation analysis table above, the result shows that there exist a significant relationship between organization culture and leadership behaviour and organization success since there is a value of 0.824 . In addition, the null hypothesis does not hold and is therefore rejected because the p-value $0.000<0.05$ where 0.05 is the selected level of significance to test for any form of relationship between the variables. Therefore, the 
result reveals that the relationship between the organization culture and leadership behaviour and its success is statistically significant.

Also, the regression analysis table as presented above, the result showcases that there are evidences of relationship between organization success (the dependent variable) and culture and leadership behaviour (the independent variable). The correlation coefficients indicate that both variables are statistically significant. Also, given that the beta value is 0.740 shows that the organization's culture and leadership behaviour has a $74 \%$ effect on the success of the organization. In addition, the null hypothesis does not hold and is therefore also rejected since the p-value $0.000<0.05$ where 0.05 is the selected level of significance to test for any form of relationship between the variables. Therefore, the result reveals a strong relationship between the organization's culture, leadership behaviour and its success.

In summary, it is conclusive to indicate that there is a strong link between the culture exhibited in the organization, its leadership style or behaviour and the success of the organization.

\subsection{FINDINGS AND DISCUSSION}

To discuss the findings, the researchers structured the discussion according to the research questions; this allows for the researchers to achieve both the objectives of the research and also to provide relevant answers to the questions that have been raised.

\subsection{Research Question 1: Is there any significance of organizational culture on the overall success of an organization?}

Having tested the first hypothesis, the correlation analysis suggested that there is a significant relationship between organization culture and the overall success of an organization. According to Gupta (2011), organizational culture expresses shared norms, values and assumptions which serve as important elements that bind an organization together. How the employee of an organization behave is spelt out by the organizational culture, and a strong and effective culture enhance common codes of conducts that guides the employee, and this will, in turn, bring about organizational success.

Organizational culture plays an important role in the strategic management of companies. In fact, organizational culture is a factor that determines the survival or failure of organizations. Moreover, to a certain extent, the strategic management is determined by the culture of organization. Critically, the impact of culture on organizational success and strategic management can be analysed based on four (4) aspects including customers, partners, employees and corporate social responsibility.

Within the organizational culture, people and groups interact with each other, including clients, partners and employees. It means that good organizational culture can bring into following benefits, including perfect customer service, efficient cooperation with partners, consistent employee performance and strong social responsibility (Yildirim \&Birinci, 2013).

Cultures can be considered as some internal agreement in the way the organization carries out its activities. Each employee brings a different set of personal experiences and a variety of backgrounds to the company; meanwhile, the consistency of these individual differences enlarges the organizational customer service. It is an undeniable fact that organizational culture has positive impact on customers; as such, a strong organizational culture will generally attract the customers and increase their loyalty to the organization. In fact, excellent customer service is provided by the employees in the common organizational culture. Customer service is not only the responsibility of the employee in the customer service department, it is the responsibility of every employee in the organization (Block, 2013). In other words, a healthy and strong organizational culture focuses on providing excellent customer service; the reason being that organizations with a strong culture tend to spend time orientating, training and reinforcing employees on how to provide excellent service for customers. The good organizational culture focuses on the development in long term. In order to achieve this goal, company generates motivation to provide high quality products or service for customers. With well-trained employees, organizations can offer talented and exceptional customer service and create a desideratum for a successful outcome.

Employees are affected by organizational culture particularly regarding how to treat tasks and achieve the business objectives. It means that organizational culture influences the decision-making process of an 
organization; as such, when organizations are faced with difficulties or opportunities, they tend to react differently depending on the culture inherent. Only when employees acclimatize the organizational culture then do they have job satisfaction; the reason is that staffs identify with the culture and values (Gupta, 2011).

In a way, organizational culture impacts the degree of employee's creative ability, task motivation, and work enthusiasm. Individuals always are attracted to engage in organizations with good and strong organizational culture. In a strong organizational culture, employees are positive to respond to their jobs. In this situation, organizational culture contributes more to effective and efficient business operation. An organization with strong cultures owns its obvious beliefs and values. Thus, accepting and embracing the culture is the choice or responsibility of the employee. Especially for the organizations in the service field, the strong culture inspires employees to deliver high quality service and be responsible for the organizational success (Hogan \&Coote, 2014). In other words, developing strong and productive cultures make the organization in accord with its vision and goals. The motivation and loyalty of employees are stirred up. It is easy for organizations to promote consistency and encourage coordination. In this situation, the strong organizational culture enables the organization to be more efficient. In addition, the team spirit in different departments can be increased via a strong organizational culture. Contrarily, a weak culture cannot lead to an alignment between the organization and its employees; this is because, if employees fail to fit into the organizational culture, they do not seem to have a sense of belonging in the organization, hence, resulting into lower job satisfaction (Block, 2013).

\subsection{Research Question 2: What is the relationship between leadership behaviour and organizational success?}

Based on the second hypothesis stating that there is no significant relationship between leadership behaviour and organizational success; the result from the analysis suggested that there is significant relationship between leadership behaviour and organizational success. It is therefore, important to establish that the various leadership styles have significant and substantial effects in any small business and also in the world's largest corporations. These styles affect everyone from senior and top management to the new entrants, both employees and new firms. These styles also form the corporate culture which in turn influences organizational and employee performance within a variety of workplace contexts.

In relations to the study of Daft \& Lane (2008), leaders are considered to be sociable, provide open communication, develop teamwork, and are oriented toward their subordinates. Tjosvold (1986) theorized that if power were to be defined in field theory rather than in behavioural terms, it is more like the control of valued resources where A possesses power as against B based on its resources that can affect the influence the magnitude of accomplishment that can be attained by B. The contributions of the contingency or situational approach came into existence as it significantly displaced the dominant trait and behaviour approach. The approach presupposes that effective leadership is dependent on a match between the style of leadership and situational factors. It also focuses on the degree to which the situation gives control and influence to the leaders. This effectively translates into work and brings out success in individual as well as in the organization. Every trait of a leader is imperative to the successful running and output of an organization.

According to Hirtz et al. (2007) and Lakshman (2006) research on the effects of specific leadership behaviours on quality performance has not been particularly comprehensive. The work of Lakshman (2006) does present a theoretical model which integrates valuesfrom TQM, leader traits, and leader behaviours with the outcomes of leader effectiveness sand unit performance. Larsson et al. (2007) the Theory Y as propounded by McGregor's (1960) presumes that a relationship exists between leadership values and methodologies as it relates to organizational positive outcomes and work quality. Hirtz et al. (2007) analysed the belongings of transformational, transactional and non-transactional management styles on quality presentation using the full range model of management. The results showed that transformational leadership is positively related to the successful implementation of quality management and that passive styles of leadership (management-byexception and laissez-faire) were negatively related. Earlier studies showedthat transformational styles of leadership and contingent reward were positively correlated with measured quality management factors. They were significant in their predictability of quality management implementation (Hirtz et al., 2007).

Different situations require different leadership styles. when there is little time to coverage on an agreement and quick work is required and where a designated authority has significantly more experience or expertise than the rest of the team, an autocratic leadership style may be most effective, however, in a highly motivated and aligned team with a homogeneous level of expertise, a more participative and democratic style may be more effective (Nuckcheddy, 2018). The style be supposed to be one that most efficiently meets the objectives of the team while complementary the attention of its followers and team members of that group 
which led by an effective leader. The autocratic style effects also known as authoritarian leadership is clearly defined by the division between leaders and workers. This kind of leaders solely make the decisions and leave out any form of involvement on the part of the employees. They pose to be more confident, surer about and comfortable with the decision-making responsibility for the strategy plans and company operating. Although research indicates that autocratic leaders display less creativity than more contemporary (new) styles (IszattWhite, 2010).

Nuckcheddy (2018) posits that the democratic style of leadership promotes the sharing of responsibility, the exercise of delegation and continual consultation. In this style, managers suggestions and recommendations on all major issues and decisions are effectively delegated as tasks to subordinates who are given full or partial control and responsibility for those tasks; hence, this encourage others to become good leaders and be involved in leadership and employee development. It was opined that this leadership style promotes employees' commitment to departmental goals and performance to meeting deadlines.

According to Al-Hussami, Hammad \&Alsoleihat (2014), it was stated that a participative style will be unproductive in the short term, but in longer time period, this style is more productive for an organization. This productivity increases due to feeling of empowerment and more commitment to their work and departmental goals. It was further ascertained that the leadership style allows for leaders to invite and encourage the team members to play an important role in the decision-making process, although the ultimate decisionmaking power rests with the leaders. Leaders tell and guide the employees what to do, and how to do the assigned task. Nonetheless, employees communicate to the leaders their experience, suggestions and recommendations. The main benefits of this leadership style are that it leads to satisfied, motivated and more skilled employees. Notably, this leadership style often leads to an optimistic and open work environment and also encourages creativity. However, the main criticism of the participative leadership style pertains to its being more time-consuming (Warrick, 2017).

\subsection{Research Question 3: Is there a link between the culture and leadership behaviour inherent in an organization on its general performance?}

The third hypothesis stated that there is no link between the culture and leadership behaviour inherent in an organization on its general performance. This is tested by correlation analysis and it shows that there exists a significant relationship between organization culture and leadership behaviour and organization success. Therefore, the result reveals that the relationship between the organization culture and leadership behaviour and its success is statistically significant.

In recent times, scholars have come to learn and prove that leadership and organizational culture are critical elements within an organization to achieve and sustain competitive advantage. Having examined the interconnection between the aforementioned elements and creating an empirical link based on data drawn from a competitive industry, the results indicate that there exists a significant relationship between these elements while the organizational cultural type and style of leadership enforces the existing relationship. Moreover, it was investigated to determine if the market conditions, such as the strength of competition and operational age and size can determine the extent and the direction of the relationship.

Over the last few decades, organizations and institutions around the world have invested in leadership and organizational culture, leading to a continuous debate about their relationship. The process of identifying and developing future leaders has traditionally evolved around the characteristics of the potential leader. IszattWhite (2010) pointed out the effect of culture on leadership, by laying emphasis on the fact that cultural values, trends, and rules are shaping a unique leadership style. Organizational culture supported the idea that leaders must evaluate and respect cultural elements, while they should try to promote an appropriate and strategically suitable culture. It was claimed that leaders are shaping culture during the first stages of business creation, but later, when the business matures, it is culture that shapes leadership characteristics. In addition, Ogbonna \& Harris (2000) relayed that the impact of leadership on a firm's performance is mediated by organizational culture. It was further implied that the initially, shaped culture will develop the next generation of corporate leaders.

The coordination between leadership and culture is an unexplored phenomenon even though corresponding coordination has been studied about the relationship between culture and organizational strategy (Gupta, 2011). Furthermore, the organizational viability and the operational growth demand a bilateral relationship, but the strength of each element depends on a series of market conditions (Huang et al., 2005). As 
the results imply, each type of culture is strongly and positively affected by the equivalent type of leadership, while lack of coordination between the two elements results in a negative impact; moreover, this has a significant importance in change management. New leadership styles can create a divergence and alter organizational harmony as new cultural elements may become obstacles for the effective management of leadership. Before any managerial change should take place, the cultural type ought to be examined in order to reveal the operational framework; otherwise, change, resistance, and frictions may occur (Nuckcheddy, 2018).

Prior to the discussions, it is essential to evaluate the relevance of various theories related to challenges in human resource management using the criteria derived from industry-based knowledge and skills. The findings, one the one hand, support the Schein's theory of organizational culture particularly with respect to the kind of espoused values that are inherent. Moreover, the organization culture is dependent on the strategy mechanisms, objectives and shared beliefs among the employees and employer. Also, elements of artifacts dealing specifically with the business environment were deemed evident according to the result. On the other hand, the behaviour theory exposes the findings to the kind of behaviour elicited by the leaders. More importantly, the duties of leaders and activities that are displayed in the organization are deemed to affect the level of organizational success. It was observed that the extent of activities that leaders in the organization undertake portrays their behaviour and may either positively or negatively affect their relationship with the subordinates and general work performance.

\subsection{CONCLUSIONS}

The research's implications are useful in dynamic and rapidly changing industries, such as the manufacturing industry, because by defining leadership style and by developing desirable cultural elements, employees can be motivated to cultivate an efficient mentality and a competitive culture. The comprehension of leadership style and cultural type can be proved as a useful tool in the global economic environment, where mergers, acquisitions, and strategic alliances occur. It is important that managers, regulators and competitors harness the evidence given the environmental situations towards making critical decisions. Lack of coordination between these leadership behaviour and organizational culture can lead to change-avoidance phenomena, conflicts between top management and employees, and reduced operational efficiency.

Cultural type is affected by degree competition, with internal-oriented cultures being negatively affected and external-oriented cultures being positively affected, while the exactly opposite results are revealed to the relationship between leadership and market competition. This situation should be considered from managers during human resource management and strategic planning. The results imply that as market competition grows, managers tend to develop more hierarchical leadership patterns in an attempt to control procedures, while the overall organizational culture tends to become more market oriented in order to respond to competition. These tendencies should be taken into account in order to prevent the existence of an operational gap between top management's leadership patterns and the rest of the companies' cultural orientation.

This study has shown that for any organization to survive, a positive impact of leadership on the employee must be achieved. We expect that this research will make significant contributions to the field of organizational development and provide a better understanding geared towards employing the right leadership style that promotes employee engagement and organizational success. The study also shows that it is necessary to effect changes in impact of leadership when the need arises in an organization in order to enhance success.

\section{REFERENCES}

[1] Al-Hussami, M., Hammad, S.\&Alsoleihat, F. (2014). Theinfluence of leadership behaviour, organizational commitment, organizational support, subjective career success on organizational readiness for change in healthcare organizations. Leadership in Health Services, 31(4), 354-370.

[2] Ali, A., Sidow, M. \&Guleid, H. (2013). Leadership styles and job satisfaction. European Journal of Management Sciences and Economics, 1(1), 1-10.

[3] Alnasseri, N., Osborne, A. \& Steel, G. (2013). Organizational culture, leadership style and effectiveness. Association of Researchers in Construction Management Journal, 1(2), 393-403.

[4] Aydin, B. (2018). The role of organizational culture on leadership styles. MANAS Journal of Social Studies, 7(1), 267-280.

[5] Block, L. (2013). The leadership-culture connection: An exploratory investigation. Leadership \& Organization Development Journal, 24, 318-334. 
[6] Bryman \& Bell (2015). Business research methods. Oxford University Press.

[7] Burke, R. (2006). Why leaders fail: exploring the dark side. International Journal of Manpower, 27(1), 91-100.

[8] Cascio, W. (2006). Managing human resources: productivity, quality of life, profits. McGraw-Hill Irwin.

[9] Cemal, Z. \&Öznur, G. (2011). Leadership behavior and organizational culture over organization success. Procedia Social and Behavioral Sciences Journal, 24(1), 1460-1474.

[10] Chin, R. (2015). Examining teamwork and leadership in the fields of public administration, leadership, and management. Team Performance Management, 21(3/4), 199-216.

[11] Christensen, C. (2006). What is an organization's culture? Boston: Harvard Business Press, August.

[12] Collings, D.G., Mellahi, K. \& Cascio, W.F. (2018). Global talent management and performance in multinational enterprises: a multilevel perspective. Journal of Management, doi. 10.1177/0149206318757018

[13] Daft, R. (2000). Organization theory and design. (7th Ed.) South-Western College Publishing, Thomson Learning. U.S.A.

[14] Daft, R. (2005). The leadership experience. 3rd ed. Thomson-Southwestern, Canada.

[15] Daft, R. \& Lane, P. (2008). The leadership experience. 4th ed. Mason: Thomson Higher Education.

[16] Dorfman, W. \&Hanges, J. (2011). Culture and leadership: A connection information processing model. Advance in Global Leadership, 4(7), 7-37.

[17] Ezirim, C., Nwibere, B. \&Emecheta, B. (2010). Organizational culture and performance: The Nigerian experience. International Journal of Business and Public Administration, 7(1), 20-23.

[18] Faraz, N.A., Yanxia, C., Ahmed, F., Estifo, Z.G., \& Raza, A. (2018). The influence of transactional leadership on innovative work behaviour - a mediation model. European Journal of Business and Social Sciences, 7(1), 51-62.

[19] Gibson, J. (2003). Organizations: Behavior structure process (11 ${ }^{\text {th }}$ ed.) Boston, Mass.: McGraw-Hill.

[20] Gifford, B., Zammuto, R., \& Goodman, E. (2002). The relationship between hospital unit culture and nurses' quality of work life. Journal of Healthcare Management, 47(1), 13-25.

[21] Gregory, B. (2009). Organizational culture and effectiveness: a study of values, attitudes, and organizational outcomes. Journal of Business Research, 62(1),673-679.

[22] Gupta, B. (2011). A comparative study of organizational strategy and culture across industry. Benchmarking: An International Journal, 18 .

[23] Hirtz, P.D., Murray, S.L., \& Riordan, C.A., (2007). The effects of leadership on quality. Engineering Management Journal, 19(1), $22-27$

[24] Hogan, J.S., \&Coote, L.V. (2014). Culture, innovation, and performance: a test of Schein's model. Journal of Business Research, 67(8), 1609-1621.

[25] Huang, M.P., Cheng, B.S., \& Chou, L.F. (2005). Fitting in organizational values. The mediating role of person-organization fit between CEO charismatic leadership and employee outcomes. International Journal of Manpower, 26, 35-49

[26] Huey, L. (2008). The association between organizational culture, leadership behavior, organizational commitment and employee performance. University of Malaya- Malaysia.

[27] Ilham, R. (2018). The impact of organizational culture and leadership style on job satisfaction and employee performance. Journal of Advanced Management Science, 6(1), 50-53.

[28] Iszatt-White, M. (2010). Strategic leadership: the accomplishment of strategy as a 'perennially unfinished project'. Leadership, 6, 409-424.

[29] James, R. \& Jones, G. (2005). The character of a corporation: how your company's culture can make or break your business. London: Harper Business.

[30] Jogulu, U. (2010). Culturally linked leadership style. Leadership and Organizational Development Journal, 31(8), 705-719.

[31] Kalsoom, Z., Khan, M.A., \& Zubair, S.S. (2018). Impact of transactional leadership and transformational leadership on employee performance: a case of FMCG industry of Pakistan. Industrial Engineering Letters, 8(3), 23-30. 
[32] Katarzyna, S. (2015). Leadership and organizational culture as the normative influence of top management on employee's behavior in the innovation process. Business Economics and Management Journal, 34(2), 396 - 402.

[33] Kefela, G. (2010). Understanding organizational culture and leadership - enhance efficiency and productivity. PM World Today, $110(1), 1-14$.

[34] Kirkbride, P. (2006). Developing transformational leaders: the full range leadership model in action. Journal of Industrial \& Commercial Training, 38(2), 23-32.

[35] Lakshman, C. (2006). A theory of leadership for quality: lessons from TQM for leadership theory. Total Quality Management \& Business Excellence, 17(1), 41-60.

[36] Larsson, J., Vinberg, S., \&Wiklund, H. (2007). Leadership, quality and health: Using McGregor's X and Y theory for analyzing values in relation to methodologies and outcomes. Total Quality Management \& Business Excellence, 18(10), 1147-1168.

[37] Li, Y. (2004). Examining the effect of organization culture and leadership behaviors on organizational commitment, job satisfaction, and job performance at small and middle-sized firms of Taiwan. Journal of American Academy of Business, 5(2), $432-801$.

[38] Lok, P. \& Crawford, J. (2004). The effect of organizational culture and leadership on job satisfaction and organizational commitment. Journal of Management Development, 23(4), 321338.

[39] Martins, E., \& Terblanche, F. (2003). Building organizational culture that stimulates creativity and innovation. European Journal of Innovation Management, 6, pp. 64-74.

[40] McGregor, D. (1960). The human side of enterprise. New York: McGraw-Hill.

[41] Natchaphan, W. (2016). The relationships between leadership behavior and subordinates' commitment: The Thai Mining Industry. College of Business Victoria University Melbourne, Australia

[42] Nuckcheddy, A. (2018). The effect of personality on motivation and organisationalbehaviour. Psychology and Behavioral Science International Journal, 9(2)1-5.

[43] Ogbonna, E. \& Harris, L. (2000). Leadership style, organizational culture and performance. The International Journal of Human Resource Management, 11(4), 766-788.

[44] Raymer, S.D. (2014). The combined effects of leadership style and organizational culture type on psychological empowerment and organizational success. Colorado State University Fort Collins, Colorado Fall 2014.

[45] Ricardo, R. \& Wade, D. (2001). Corporate performance management: how to build a better organization through measurement driven strategies alignment. Butterworth Heinemann.

[46] Robbin, S. (2001). Organizational behavior. $9^{\text {th }}$ ed., Upper Saddle River, N.J, Prentice Hall.

[47] Robbins, S. (2005). Organizational behavior. 11th ed., Pearson Prentice Hall, New Jersey.

[48] Rousseau, D. (1991). Quantitative assessment of organizational culture. Group and Organizations Studies, 15(4), 448-460.

[49] Saunders, M., Lewis, P. and Thornhill, A. (2016). Research methods for business students. Harlow: Pearson Education Limited.

[50] Schein, E. (1990). Organizational culture. American Psychologist, 45, 109-119. Doi: 10.1037/0003-066X.45.2.109,

[51] Schimmoeller, L. (2010). Leadership styles in competing organizational culture. Leadership Review, 10(1), $125-141$.

[52] Tjosvold, D. (1986). Organizational test of goal linkage theory. Journal of Occupational Behaviour, 7(2), 77-88.

[53] Trevisani, D. (2016). Communication for leadership: coaching leadership skills. 2nd ed., Ferrara: Medialab Research.

[54] Tuan, L.T. (2010). Organisational culture, leadership and performance measurement integratedness. International Journal of Management and Enterprise Development, 9(3), 251-275.

[55] Volio, B. J., \& Bass, B. M. (2004). Multifactor leadership questionnaire. Manual and Sampler Set (3rd ed.). Redwood City, CA: Mindgarden.

[56] Walumbwa, F. \&Orwa, B. (2008). Contingent reward transactional leadership, work attitudes, and organizational citizenship behavior: the role of procedural justice climate perceptions and strength. The leadership Quarterly, 19(1), 251-265.

[57] Warrick, D.D. (2017). What leaders need to know about organization culture. Business Horizons. Retrieved from: 60. 10.1016/j.bushor.2017.01.011. 
[58] Yafang, T. (2011). Relationship between culture, leadership behavior and job satisfaction. Tsai BMC Health Services Research journal, 11(8), $18-25$.

[59] Yildirim, N. \&Birinci, S. (2013). Impacts of organizational culture and leadership on business performance: a case study on acquisitions. Procedia - Social and Behavioral Sciences, 75, 71 - 82.

[60] Yong, S., Moktar, S. \& Ahmad, S. (2017). Effectiveness of talent management to improving organisational performance in government owned bank. Research Journal of Business Management, 7, 32-38.

[61] Yu, L. (2013). Organizational culture, leadership behaviors, and employee attitude in Chinese SMEs. China USA Business Review, 12(11), 1085-1095.

[62] Zeyada, M. (2018). Organizational culture and its impact on organizational citizenship behavior. International Journal of Academic Research in Business and Social Sciences, 8(3), 418-429. 